\title{
A JUDICIALIZAÇÃO DA ASSISTÊNCIA FARMACÊUTICA AO PACIENTE DIABÉTICO NO ESTADO DO PARÁ: 10 ANOS DA AÇÃO CIVIL PÚBLICA No 0006454-87.2008.4.01.3900.
}

\author{
Andreza Casanova Von Grapp Santos ${ }^{1}$
}

\section{RESUMO}

A pesquisa pretende analisar os efeitos da judicialização da assistência farmacêutica ao portador de Diabetes Mellitus no Estado do Pará tendo como referência a Ação Civil Pública $\mathrm{n}^{\circ}$ 0006454-87.2008.4.01.3900 e verificar como as políticas públicas destinadas aos diabéticos evoluíram no período de 2008, quando a ação foi interposta, até a presente data. Será realizada pesquisa bibliográfica sobre a judicialização da saúde, federalismo, políticas públicas destinadas aos pacientes diabéticos e aplicação do princípio da responsabilidade solidária entre os entes federados e análise dos regulamentos expedidos pelo Ministério da Saúde que regulam o fornecimento de medicamentos aos diabéticos.

Palavras-chave: Políticas Públicas, Judicialização da Saúde, Federalismo, Responsabilidade solidária, Atenção ao Diabético.

\section{THE JUDICIALIZATION OF PHARMACEUTICAL ASSISTANCE TO DIABETIC PATIENTS IN THE STATE OF PARÁ: 10 YEARS OF PUBLIC CIVIL ACTION Nº 0006454-87.2008.4.01.3900.}

\begin{abstract}
The research aims to analyze the effects of the judicialization of pharmaceutical assistance to patients with Diabetes Mellitus in the State of Pará by reference to Public Civil Action No. 0006454-87.2008.4.01.3900 and to verify how public policies aimed at diabetics evolved in 2008, when the action was brought to date. Bibliographic research will be conducted on the judicialization of health, federalism, public policies aimed at diabetic patients and application of the principle of joint responsibility between federated entities and review of regulations issued by the Ministry of Health that regulate or provide medicines for diabetics.
\end{abstract}

Keywords: Public Policies, Health Judicialization, Federalism, Solidary Responsibility, Diabetic Care.

\section{INTRODUÇÃO}

\footnotetext{
${ }^{1}$ Mestre em Direito, Políticas Públicas e Desenvolvimento Regional pelo Centro Universitário do Estado do Pará. Graduada em Farmácia e em Direito pelo Centro Universitário do Estado do Pará. Farmacêutica na Procuradoria Geral do Estado do Pará assessorando o Subnúcleo de Direitos Sociais. Professora das disciplinas de Proteção à Propriedade Intelectual e Bioética/Biodireito do Centro Universitário do Estado do Pará. Contato: andrezavongrapp@gmail.com
} 
O medicamento é uma das tecnologias mais utilizadas pelo setor de saúde e considerado essencial para a prática da medicina ocidental, mas garantir o seu acesso ainda é um desafio, mesmo com os avanços tecnológicos que permitem a descoberta de moléculas inovadoras e a cura de doenças antes impensáveis. Dessa forma, a via judicial tem representado, muitas vezes, o meio de acesso, não só das tecnologias de alto custo indisponíveis no serviço público, mas de medicamentos básicos que, mesmo contemplados em programas do SUS, faltam nos estoques das Unidades de Saúde.

Pesquisar o tema permite compreender os desafios da universalização da saúde que fica refletido no número crescente de demandas judiciais que tramitam nas varas e tribunais do país pleiteando medicamentos, insumos e serviços em saúde e que suscitam questionamentos importantes, entre eles a discussão em torno do protagonismo judicial, da delimitação da responsabilidade de cada ente público nas questões que envolvem o direito à saúde, da alocação de recursos necessários ao cumprimento das demandas e, embora tratar-se de um tema intensamente debatido a partir da década de 1990, com as primeiras demandas visando garantir o tratamento de pacientes com Síndrome da Imunodeficiência Adquirida (HIV/AIDS), o crescimento do número de ações nos tribunais de todo o país alcança valores relevantes como se depreende de informações recentemente divulgadas pelo Tribunal de Contas da União (TCU) ${ }^{2}$ que realizou auditoria operacional que abrangeu a União, Estados e Municípios com o objetivo de identificar o perfil, o volume e o impacto das ações judiciais na área da saúde e investigar a atuação do Ministério da Saúde e de órgãos e entidades dos três poderes para mitigar os efeitos negativos da judicialização nos orçamentos e no acesso dos usuários à assistência à saúde. Foi constatado que a União gastou com o cumprimento de decisões judiciais para aquisição de medicamentos e insumos, no período de 2010 a 2015, R\$ 2,7 bilhões.

Dados obtidos por meio de consulta ao endereço eletrônico disponibilizado pelo Governo Federal para acesso à informação em cumprimento à Lei de Acesso à informação no 12527, de 18 de novembro de 2011 - Anexo I, demostram que as insulinas corresponderam a $40 \%$ dos processos de compra realizados pela União para o atendimento de demandas judiciais, no ano de 2015.

As insulinas fazem parte do rol de terapias destinadas ao tratamento da Diabetes Mellitus -DM, uma das doenças crônicas mais prevalentes no mundo e se constitui em um dos

\footnotetext{
${ }^{2}$ Cf. https://portal.tcu.gov.br/imprensa/noticias/aumentam-os-gastos-publicos-com-judicializacao-da-saude.htm
} 
maiores desafios de saúde pública do século XXI. Whiting David R. et al (2011), da Federação Internacional de Diabetes, informam que em 2011, eram 366 milhões de pessoas com diabetes, e isso deve aumentar para 552 milhões até 2030 destacando que "a maioria das pessoas com diabetes vive em países de baixa e média renda, e esses países terão o maior aumento nos próximos 19 anos".

Além das taxas crescentes de mortalidade, o DM preocupa devido ao custo econômico associado à doença, com o aumento da incidência há um crescimento maciço das despesas de saúde relacionadas a atenção ao paciente diabético. A desigualdade nas condições de vida em nossa sociedade favorece o surgimento de pessoas ou populações em situação de maior vulnerabilidade social, quanto maior o número de pessoas vivendo em situações de vulnerabilidade, maior a morbidade e a mortalidade.

O impacto econômico do DM sobre a sociedade atual é enorme e incide principalmente nos sistemas de saúde públicos, como o Sistema Único de Saúde - SUS que trabalha com a Relação Nacional de Medicamentos Essenciais (RENAME), lista que norteia a oferta de medicamentos para o tratamento dos principais problemas de saúde da população, mas que sofre interferência do lobby da indústria e do comércio de produtos farmacêuticos fazendo muitas vezes faz com que usuários e prescritores passem a considerar imprescindível o uso dos novos produtos lançados no mercado, tornando-se frequente a reivindicação dos mesmos via judiciário. A solicitação dos análogos de insulina e dos novos agentes antidiabéticos orais (metiglinidas, glitazonas, gliptinas etc.) é um exemplo dessa situação

No Estado do Pará o tema é objeto de intensa judicialização, são inúmeras ações individuais e coletivas compelindo o Ente Federado a fornecer medicamentos e insumos que não estão padronizadas em políticas públicas do SUS, sendo a Ação Civil Pública $n^{\circ}$ 0006454-87.2008.4.01.3900, a mais relevante delas e por esse motivo objeto de estudo do presente artigo.

A ausência de estudos empíricos, seja nos debates e até mesmo no bojo das ações de saúde, limita a discussão ao plano teórico o que dificulta a percepção das causas reais da judicialização e suas consequências. Acrescentar dados da realidade visa estimular uma discussão consciente do problema do acesso ao medicamento, contribuindo com o desenvolvimento de uma judicialização responsável e que de fato busque a concretização do direito à saúde como um direito coletivo. 
Se, por um lado, a atuação do Poder Judiciário é fundamental para o exercício efetivo da cidadania, por outro as decisões judiciais têm significado um forte ponto de tensão entre os elaboradores e os executores das políticas públicas, que se veem compelidos a garantir prestações, muitas vezes contrastantes com a política estabelecida pelos governos para área da saúde. O estudo tratará dos efeitos práticos da judicialização sobre a de assistência farmacêutica aos diabéticos analisando as mudanças que ocorreram na oferta de medicamentos à população e na execução da política pública buscando responder em que medida o cenário constituído pela judicialização da saúde interferiu no acesso a medicamentos destinados aos diabéticos no SUS.

O trabalho foi organizado em três capítulos, o primeiro abordará o federalismo aplicado na manutenção do SUS. O segundo capítulo apresentará as políticas de assistência farmacêutica aos diabéticos e a Ação Civil Pública em comento. O terceiro tratará da judicialização e da discussão sobre a responsabilidade solidária.

\section{O FEDERALISMO APLICADO NA MANUTENÇÃO DO SUS}

A Constituição Federal de 1988 é considerada um marco institucional na luta pelos direitos sociais da população brasileira e o Estado Federal foi o modelo escolhido pelo constituinte, em função de razões históricas, culturais, econômicas e geográficas, para viabilizar a concretização dos direitos dispostos na Constituição como demostra Palácios (2016, p.5), destacando que em virtude da complexidade social, econômica, política e administrativa, o Estado tem sido demandado a oferecer melhores serviços públicos e possibilitar que os direitos sociais sejam usufruídos em sua plenitude, alguns processos e instrumentos de relações intergovernamentais entre os entes da federação têm sido experimentados, considerando suas respectivas competências institucionais.

Nessa seara o direito à saúde restou consagrado como uma obrigação do Estado e um direito do cidadão como prevê o art. 196 da Carta Constitucional. Aliás a Organização Mundial de Saúde (OMS) vem propugnando, há anos, a adoção pelos países soberanos de sistemas universais de saúde. Desde a segunda guerra mundial, os direitos humanos ganharam relevância, se desenvolveram e passaram a ser o palco do combate à discriminação e ao desrespeito à dignidade humana. 
O Brasil adotou um modelo de assistência de saúde pública reconhecido internacionalmente, o SUS - Serviço Único de Saúde. Disposto no art. 198 e tendo suas atribuições definidas no art. 200 da Constituição Federal de $1988^{3}$ (Brasil, 1998), é regulado pela Lei $n^{\circ}$ 8080/90 (Brasil, 1990) e está concebido com base nos princípios da universalidade, equidade, integralidade e voltado para as necessidades da população, mas o Estado brasileiro ainda está longe de efetivar a plenitude de acesso à saúde, o que se evidencia no exponencial crescimento da chamada "judicialização da saúde", com reiterado ajuizamento de demandas por meio das quais a população pretende assegurar, junto ao Poder Judiciário, o acesso a tratamentos, internações, transportes e medicamentos.

Sem embargo, a judicialização da saúde suscita questionamentos importantes, dentre eles a discussão em torno da delimitação da responsabilidade de cada ente público nas questões que envolvem o direito à saúde.

A CF/88, seguindo um modelo de federalismo cooperativo, determinou em seu art. 23, que a competência para cuidar da saúde é comum à União, Estados, Distrito Federal e Municípios, ou seja, as atividades e serviços públicos em saúde devem ser fomentados e executados mediante atuação conjunta de todas as esferas da federação. Porém, ela não define, diretamente, quais são os campos ou as tarefas específicas de cada esfera federativa em cada uma das hipóteses de competência comum, ficando a cargo do legislador infraconstitucional estabelecer a política pública a ser seguida e quais serão as atribuições de cada esfera.

A jurisprudência já está firmada quanto à solidariedade dos entes da Federação na prestação do direito à saúde. Os tribunais têm reiteradamente decidido que pedidos de fornecimento de medicamentos e tratamentos de saúde podem ser pleiteados a todos os entes federativos, em conjunto ou separadamente. O Supremo Tribunal Federal julgou que há repercussão geral no RE 855.178 em que se discuti, à luz dos arts $2^{\circ}$ e 198 da Constituição Federal, a existência ou não, de responsabilidade solidária entre os entes federados pela promoção dos atos necessários à concretização do direito à saúde.

Tomando como base a teoria do Estado federal moderno, pode-se afirmar que o federalismo diz respeito a uma forma particular de organização político-territorial do poder do Estado, que o distingue do modelo unitário e do confederativo em relação aos aspectos fundamentais de sua estrutura e funcionamento. O federalismo reparte a autoridade política 
do Estado (a soberania) e o exercício do poder (o governo) em múltiplos centros soberanos definidos geograficamente e coordenados entre si em um mesmo território nacional (LIMA, 2012).

A instabilidade dos arranjos federativos e dos processos de centralização e descentralização sugere a diversidade de valores dentro de uma federação, que variam de acordo com as circunstâncias históricas, com a dinâmica da economia política, dos partidos e da cultura política. Esses aspectos são importantes nas análises das instituições, pois ajudam a entender as motivações ou os padrões de interesse que embasam a existência de uma federação em particular (LIMA, 2012).

A Constituição de 1988 adotou o modelo federal de Estado junto com inúmeros direitos, deveres e obrigações ao Estado e a sociedade. Seu intuito era de mudança social e econômica da realidade brasileira. Para tanto repartiu em três esferas autônomas o Estado, com o intuito de melhor atender a consecução dos direitos então dispostos (PALÁCIOS, 2012).

Do ponto de vista federativo, a Constituição atribuiu competência para legislar sobre proteção e defesa da saúde, concorrentemente à União, aos Estados e aos municípios (CF/88, art. 24, XII, e 30, II). À União cabe o estabelecimento de normas gerais (art. 24, §1 ${ }^{\circ}$ ); aos Estados, suplementar a legislação federal (art. 24, § 2º ; e aos Municípios, legislar sobre os assuntos de interesse local, podendo igualmente suplementar a legislação federal e a estadual, no que couber (art. 30, I e II) (BARROSOS, 2009).

Logo após a entrada em vigor da Constituição Federal, em setembro de 1990, foi aprovada a Lei Orgânica da Saúde (Lei no 8080/90). A Lei estabelece a estrutura e o modelo operacional do SUS, propondo sua forma de organização e de funcionamento (BARROSO, 2209).

A Lei 8080/90, além de estruturar o SUS e de fixar suas atribuições, estabelece os princípios pelos quais sua atuação deve se orientar, dentre os quais vale destacar o da universalidade - por força do qual se garante a todas as pessoas o acesso à serviços de saúde disponíveis - e o da subsidiariedade e da municipalização, que procura atribuir prioritariamente a responsabilidade aos municípios na execução das políticas públicas de saúde em geral. (BARROSO, 2009)

A referida Lei procurou definir ainda o que cabe a cada um dos entes federativos na matéria. A direção Nacional do SUS, atribuiu a competência de "prestar cooperação técnica e 
financeira aos Estados, ao Distrito Federal e aos Municípios para o aperfeiçoamento da sua atuação institucional" (art. 16, XIII), devendo "promover a descentralização para as unidades federadas e para os municípios, dos serviços e ações de saúde, respectivamente, de abrangência estadual e municipal" (art. 16, XV). À direção estadual do SUS, a Lei 8080/90, em seu art. 17, atribuiu as competências de promover a descentralização para os Municípios dos serviços e de ações em saúde, de lhes prestar apoio técnico e financeiro, e de executar supletivamente ações e serviços de saúde. Por fim, à direção municipal do SUS, incumbiu de planejar, organizar, controlar, gerir e executar os serviços públicos de saúde (art. 18, I e III). (BARROSO, 2009)

O SUS tem sua forma organizativa expressa no art. 198 da Constituição:

Art. 198. As ações e serviços públicos de saúde integram uma rede regionalizada e hierarquizada e constituem um sistema único, organizado de acordo com as seguintes diretrizes:

I - descentralização, com direção única em cada esfera de governo;

II - atendimento integral, com prioridade para as atividades preventivas, sem prejuízo dos serviços assistenciais;

III - participação da comunidade.

As diretrizes são: a descentralização, com a direção única em cada esfera do governo; o atendimento integral no sentido de unir as atividades preventivas com as curativas, devendo se dar ênfase às atividades preventivas, mas desde que não prejudiquem as assistenciais; e a participação da comunidade. São esses os alicerces, as estruturas do SUS no país.

É importante decompor o art. 198, caput, para uma análise detalhada e sistêmica, por ser essa disposição que conformará o SUS.

A descentralização na saúde foi denominada de municipalização, no sentido de levar aos municípios responsabilidades pelo cuidado com a saúde, o que realmente foi feito pela Constituição de 88 , ao compartilhar competência pela saúde pública igualmente entre os entes federativos. (SANTOS, 2013)

Era essencial para reforma sanitária a proximidade do gestor público com o cidadão, o deslocamento ou a divisão do poder no cuidado com a saúde. Essa aproximação, estado e sociedade, permitiria uma maior participação da comunidade na administração local, com a população atuando de maneira mais efetiva nas políticas de saúde, ganhando 
maturidade e desenvolvendo um sentimento de pertencimento em relação à política pública de saúde. ${ }^{4}$

A descentralização do federalismo, territorial e política, exige plena participação dos poderes periféricos, afastados do poder central e próximos à comunidade, por ser deles a competência de realizar tudo que lhes é possível.

Nessa linha, o municipalismo ganhou força com a Constituição de 88, que adotou a teoria do federalismo tridimensional, elevando o município à condição de unidade federativa. ${ }^{5}$

Entretanto, esse modelo tridimensional tem sido bastante criticado pelas dificuldades que encerram e pelo fato de, na realidade, nosso modelo federativo ser bastante centralizado, com a União exercendo fortemente seu papel de executora das políticas públicas. Os municípios brasileiros são bastante carentes de capacidades técnico-econômicas, além de haver forte desigualdade sociodemográfica e econômica. (SANTOS, 2013)

A questão central - e isso se aplica fortemente à saúde - é que no federalismo cooperativo, que deveria se unir ao princípio da subsidiariedade no sentido de apoio, ajuda, colaboração em relação ao ente mais fraco economicamente ou tecnicamente com vistas a seu desenvolvimento, tem ensejado forte perda de autonomia, gerando acomodação em relação ao poder central, que passa a ser o que planeja, financia, define a política e a programação. Esse estado de acomodação e costume de aceitar decisões supercentralizadas dos entes federados reforça o centralismo, arrefece a subsidiariedade e concentra poderes na União, em detrimento do poder local e regional. (SANTOS, 2013)

2 A POLÍTICA PÚBLICA DE ATENÇAO AO PACIENTE COM DIABETES MELLITUS E A JUDICIALIZAÇÃO DO ACESSO AO TRATAMENTO VIA AÇÃO CIVIL PÚBLICA N ${ }^{\circ}$ 0006454-87.2008.4.01.3900.

Diabetes Mellitus (DM), de acordo com a Organização Mundial da Saúde (OMS), é o termo que descreve uma desordem metabólica de etiologia múltipla, caracterizada por hiperglicemia crônica e distúrbios no metabolismo de carboidratos, lipídios e proteínas resultantes de defeitos na secreção de insulina, na ação da insulina ou em ambos. (BRASIL, 2014)

\footnotetext{
${ }^{4}$ Idem, p. 104

5 Idem, p. 105
} 
O diabetes tipo 1 (DM1), também conhecido como diabetes mellitus insulinodependente, é uma forma menos frequente do diabetes e caracteriza-se pela hiperglicemia crônica devido a uma deficiência absoluta da produção de insulina pelo pâncreas (destruição das células $\beta$ deste órgão), necessitando assim da administração de insulina exógena ao longo da vida para a sobrevivência. (BRASIL, 2014)

A diabetes tipo 2 (DM2) é a forma mais presente destas manifestações, atingindo mais de $90 \%$ dos casos e caracteriza-se por defeitos na ação e secreção de insulina. Desenvolve-se geralmente em adultos e tem sido relacionada à obesidade, falta de atividade física e hábitos alimentares não saudáveis. $\mathrm{Na} \mathrm{DM} 2$, os pacientes não dependem de insulina exógena para sobreviver, porém podem necessitar de tratamento com insulina para obter controle metabólico adequado. ${ }^{6}$ (BRASIL, 2014)

A atenção aos portadores de DM, no âmbito do SUS é desenvolvida inicialmente na Rede Básica de Saúde através de ações de detecção, controle e prevenção realizadas pelas equipes de Atenção Primária e de Saúde da Família.

A Lei $n^{\circ} 11.347$ de 27 de setembro de 2006 dispõe sobre a distribuição gratuita de medicamentos e materiais necessários à sua aplicação e monitoramento da glicemia capilar aos portadores de diabetes inscritos em programas de educação para diabéticos e a Portaria $n^{\circ}$ 2.583, de 10 de outubro de 2007, define o elenco de medicamentos e insumos disponibilizados pelo SUS, nos termos da Lei $\mathrm{n}^{\circ}$ 11.347, aos usuários portadores da Diabetes Mellitus.

Os medicamentos e insumos destinados a atenção ao paciente biabético, com base nos referido instrumentos legais são:

I- MEDICAMENTOS: a) glibenclamida $5 \mathrm{mg}$ comprimido; b) cloridrato de metformina $500 \mathrm{mg}$ e $850 \mathrm{mg}$ comprimido; c) glicazida $80 \mathrm{mg}$ comprimido; d) insulina humana NPH - suspensão injetável $100 \mathrm{UI} / \mathrm{mL}$; e e) insulina humana regular - suspensão injetável $100 \mathrm{UI} / \mathrm{mL}$.

II - INSUMOS: a) seringas com agulha acoplada para aplicação de insulina; b) tiras reagentes de medida de glicemia capilar; e c) lancetas para punção digital.

\footnotetext{
${ }^{6} \mathrm{http} / / /$ u.saude.gov.br/images/pdf/2014/janeiro/24/Relatorio-Insulina-diabetestipoII-CP.pdf
} 
Estão contemplados no Componente Básico da Assistência Farmacêutica, cujas normas estão previstas na Portaria $n^{\circ} 1555$, de 30 de julho de 2013, sendo responsabilidade dos municípios a execução do programa aos seus munícipes.

Quanto às insulinas, a referida Portaria estabelece que cabe ao Ministério da Saúde o financiamento e a aquisição da Insulina NPH 100UI/ML e da Insulina regular 100UI/ML, além da distribuição aos almoxarifados e Centrais de Abastecimento Farmacêuticos estaduais e do Distrito Federal. As Secretarias Estaduais de Saúde farão a distribuição das insulinas NPH 100UI/ML e da insulina regular 100UI/ML aos municípios.

Em 16/06/2008, o Ministério Público da União interpõe a Ação Civil Pública - ACP, $\mathrm{n}^{\mathrm{o}}$ 0006454-87.2008.4.01.3900 , ${ }^{7}$ para cumprimento da obrigação de fazer cumulada com pedido de tutela antecipada, em face do Município de Belém, do Estado do Pará, e da União para que os Entes públicos fornecessem regularmente e de forma gratuita os medicamentos para o tratamento de DM no Estado do Pará.

A tutela antecipada foi deferida em 07/07/2008 e na decisão prolatada determinou-se que:

"União, o Estado do Pará e o Município de Belém, no prazo de 15 dias,
garantam ao menor J.L.F e J.H.R.L, o fornecimento ininterrupto, até final
decisão, dos medicamentos de nominados insulina Glargina e Insulina
Lispro ou Aspart, as agulhas descartáveis de caneta e fitas reagentes de
glicosímetro, nas quantidades prescritas, bem como, a TODOS que deles
necessitarem, o fornecimento ininterrupto, até final decisão, de TODOS OS
MEDICAMEMTOS E MATERIAIS destinados ao adequado e eficiente
tratamento de paciente diabéticos, em quantidade e qualidade necessários, de
acordo com a respectiva prescrição".

A decisão permaneceu vigente até a abril de 2016, quando foi prolatada a sentença e determinando o fornecimento dos medicamentos e insumos aos pacientes diabéticos, inclusive as insulinas análogas, que até então não haviam sido incorporadas às políticas públicas de Assistência Farmacêutica.

As insulinas análogas Glargina e Lispro ou Asparte não constavam da RENAME.

Sobre os análogos de insulina trata-se de uma forma modificada do hormônio, com objetivo de alterar seu perfil farmacocinético de absorção, distribuição, metabolismo e excreção. Tais modificações, feitas utilizando-se da engenharia genética, se dão no nível da sequência de aminoácidos da insulina humana. As insulinas análogas podem ser de curta ação

\footnotetext{
${ }^{7}$ https://processual.trf1.jus.br/consultaProcessual/processo.php
} 
e as principais representantes desse grupo são as insulinas lispro, asparte e a glulisina. No grupo das insulinas análogas de longa ação estão as insulinas glargina e detemir..

A Lei $n^{\circ} 12.401 / 2011$, que introduziu alterações na Lei $n^{\circ}$ 8.080/1990, e o do Decreto 7.646/2011 definem os critérios e prazos para a incorporação de tecnologias no sistema público de saúde e estabelece que o Ministério da Saúde, assessorado pela Comissão Nacional de Incorporação de Tecnologias - CONITEC, tem como atribuições a incorporação, exclusão ou alteração de novos medicamentos, produtos e procedimentos, bem como a constituição ou alteração de protocolo clínico ou de diretriz terapêutica.

Em 2014, a CONITEC publicou decisão de não incorporar as insulinas análogas ao elenco do SUS.

Só em 15 de março de 2018 a CONITEC estabelece um Protocolo Clínico e Diretrizes Terapêuticas para atendimento aos pacientes diabéticos incorporando as insulinas análogas para os portadores da DM - Tipo I que serão atendidos pelo Componente Especializado da Assistência Farmacêutica.

Somente após dez anos da decisão que determina à entes públicos, inclusive o Estado do Pará o atendimento aos pacientes das insulinas análogas por via judicial há a incorporação dos fármacos nas políticas públicas de assistência farmacêutica aos diabéticos.

Considerando que não houve a modulação dos efeitos da decisão, de forma a estabelecer a obrigação individualizada a cada ente não é possível identificar como se deu o cumprimento em cada esfera administrativa, o que leva a discussão sobre a solidariedade no âmbito das decisões judiciais em matéria de saúde, especialmente de medicamento.

\section{A JUDICIALIZAÇÃO E A APLICAÇÃO DA SOLIDARIEDADE ENTRE OS ENTES FEDERADOS.}

Sem olvidar do propalado direito à saúde, é elementar que a desconsideração das regras sobre competências de políticas públicas de saúde causa múltiplos transtornos aos entes da federação, que frequentemente em prazos exíguos precisam se debruçar no cumprimento de ordens judiciais a determinar infindáveis procedimentos, medicamentos e tratamentos. (FREITAS, 2014)

Sarmento e Telles (2012), citam que a jurisprudência majoritária considera que a procedência ou não dos pedidos nas causas envolvendo prestações materiais do direito à saúde independe de qual(is) ente(s) da Federação tenha(m) sido indicado no polo passivo da 
lide, pois a verificação pura e simples de que o Poder Público, em sentido amplo, deve prestar a medida requerida é considerada apta para ensejar a condenação de qualquer e de todos eles e explicam que o regime de responsabilidade vislumbrado pela jurisprudência é o de responsabilidade solidária entre os entes e encontra fundamento no art. 23, II da Constituição brasileira, que trata da competência comum entre União, Estados e Municípios [...] para cuidar da saúde, porém criticam esse entendimento, pois, afirmam não está compatível com a teleologia do dispositivo constitucional e em segundo plano, embora gere uma vantagem imediata ao cidadão litigante, confere ao SUS uma gestão pouco racional e democrática, acarretando, por consequência, prejuízos muito maiores à promoção do direito fundamental à saúde da população como um todo, concluindo que o regime da solidariedade acatado pela jurisprudência majoritária, ao passar por cima das regras de divisão de atribuições estabelecidas pelo legislativo e pelo executivo, acaba desorganizando a gestão da saúde pública no país.

Como o art. 198 da Constituição Federal prevê a organização regionalizada e hierarquizada do SUS, não há como afastar a legalidade das normas administrativas de organização do SUS coma repartição da competência entre os gestores. Nesse sentido, Dresch e Gebran (2015) mencionam que a discussão que se impõe diz respeito aos limites da solidariedade, sobretudo quando já tiverem sido implantadas políticas públicas que repartem especificamente a competência entre os gestores, distribuindo administrativamente a responsabilidade de cada um dos gestores.

Nas demandas judiciais para o acesso às ações e serviços de saúde é necessário ponderar sobre a existência de normas de repartição de competência entre os gestores, para que se possa fixar a responsabilidade de cada gestor.

Embora muitos autores façam um grande esforço para demonstrar "histórias de sucesso" na efetivação de direitos sociais por meio do Judiciário, Silva (2008) destaca que tais histórias são superestimadas.

As questões que envolvem a judicialização do acesso à saúde suscitam o debate, mas o que fica evidenciado na análise do tema é que embora a atuação do judiciário represente um importante instrumento de controle das políticas públicas na efetivação desse direito, o Estado Brasileiro ainda está longe de efetivar a plenitude do acesso à saúde. As primeiras incursões no Judiciário, visando garantir aos portadores de HIV o acesso aos medicamentos e demais insumos necessários para o tratamento da doença, ocorreram na década de 1990 e desde então 
a cada ano aumentam de forma exponencial o ajuizamento das demandas por meio das quais a população pretende assegurar junto ao Poder Judiciário, o acesso a tratamentos, internações, insumos, medicamentos etc.

Dresch (In: SCHULMAN et. al., 2017) esclarece que nos anos precedentes a 2010, o volume de demandas à saúde não era impactante ao erário, não sendo estatisticamente relevante, mas que houve uma escalada na judicialização da saúde apresentando dados do Conselho Nacional de Justiça que informam o crescimento no quantitativo de processos a partir de 2011.

Ao propor desenvolver o direito à saúde sob o enfoque das políticas públicas, o trabalho pretendeu trazer elementos da realidade para a análise do problema, afinal é por meio das políticas públicas que as diretrizes e princípios constitucionais serão concretizados e se há problemas a serem resolvidos, no sentido de tornar efetivo o direto à saúde, é a partir da lógica das políticas públicas que a questão deve ser enfrentada. Disso decorre a importância de promover a compreensão da execução das políticas públicas pelos agentes que atuam nas demandas que visam assegurar, por via judicial, o acesso a bens e serviços de saúde, especialmente de medicamentos, objeto do estudo.

\section{CONCLUSÃO}

A judicialização da saúde no Brasil tem reconfigurado as responsabilidades dos entes da federação para o estabelecimento de políticas públicas que atendam aos critérios de universalidade, integralidade e descentralização e, sem dúvida, consolidam o direito à saúde, porém podem produzir efeitos relacionados à associação linear entre competência comum e responsabilidade solidária. Em matéria de medicamento, por exemplo, a repartição de atribuições é clara e objetiva, assim ao impor fornecimento de medicamentos ou tratamentos de saúde ao Poder público, é fundamental que os órgãos do Poder Judiciário observem as normativas do SUS quanto às competências das instâncias gestoras.

Nesse campo, para evitar conflitos ou decisões que desestruturem a organização técnico-administrativa há a necessidade do redimensionamento da dialética processual onde questões de interesse público que são submetidas ao critério jurisdicional.

A densidade e a complexidade da matéria envolvida no controle jurisdicional de políticas públicas exigem uma intensa relação dialética entre os envolvidos, quais sejam: os gestores, membros do Ministério Público e da Defensoria Pública, membros do judiciário, 
associação de pacientes, gestores, profissionais de saúde etc. cotejando-se os diferentes enfoques e as realidades contraditórias e polêmicas trazidas ao debate que naturalmente envolvem as escolhas políticas.

Ao interpor a Ação Civil Pública no 0006454-87.2008.4.01.3900 o Ministério Público da União visou corrigir falhas na execução das políticas públicas então vigentes, porém durante dez anos as medidas permaneceram limitadas aos que estavam sobre o alcance dos efeitos da ação coletiva.

As insulinas análogas, objeto da decisão em tutela antecipada só foi incorporada em política pública 10 anos depois da decisão que determina o fornecimento em tutela antecipada e como não houve definição de que ente deveria fornecer os medicamentos e insumos pode ter havido duplicidade de atendimento e principalmente a ação não alcançou a política pública em questão, atendendo apenas alguns pacientes que buscavam individualmente.

\section{REFERÊNCIAS}

ASENSI, Felipe Dutra. O direito à saúde no Brasil. In: ASENSI, Felipe Dutra; PINHEIRO, Roseni (Org.). Direito Sanitário. Rio de Janeiro: Elsevier, 2012. p. 02 - 26.

BARROSO, Luís Roberto. Da falta de efetividade à judicialização excessiva: Direito à saúde, fornecimento gratuito de medicamentos e parâmetros para atuação judicial. In: SOUZA NETO, Cláudio Pereira de; SARMENTO, Daniel (Org.). Direitos Sociais: Fundamentos Jurídicos e Direitos Sociais em Espécie. Rio de Janeiro: Lumin Juris, 2009. p. 875- 903.

BRASIL. Conselho Nacional de Secretários da Saúde. Assistência Farmacêutica no SUS: Para entender a gestão do SUS. Brasília: Conass, 2011.

. Constituição da República Federativa do Brasil. Brasília: Senado, 1998.

Ministério da Saúde. Lei $\mathbf{n}^{\circ} \mathbf{8 0 8 0}$, de 19 de setembro de 1990. Dispõe sobre as condições para a promoção, proteção e recuperação da saúde, a organização e o funcionamento dos serviços correspondentes e dá outras providências (Lei Orgânica do Sus), 1990.

Presidência da República. Decreto n⿳ 7508, de 28 de junho de 2011. Regulamenta a Lei 8080 de 19 de setembro de 1990, para dispor sobre a organização do SUS, o planejamento da saúde, a assistência à saúde e a articulação interfederativa, e dá outras providências. Brasília: 2011.

Ministério da saúde. Portaria no . 3.916/GM de 30 de outubro de 1998. Aprova a Política Nacional de Medicamentos. Diário Oficial da União, Brasília, 10 nov. 1998. 
Ministério da saúde. Portaria nº 1554/GM de 30 de julho de 2013.Dispõe sobra as regras de financiamento e execução do Componente Especializado da Assistência Farmacêutica no âmbito do SUS. Diário Oficial da União, Brasília. 2013

Ministério da saúde. Portaria no. 204/GM de 29 de janeiro de 2007. Regulamenta o financiamento e a transferência de recursos federais para as ações e os serviços de saúde, na forma de bloco de financiamento, com o respectivo monitoramento e controle. Diário Oficial da União, Brasília, 10 nov. 1998.

Ministério da saúde. Lei $\mathbf{n}^{\mathbf{0}} 11.347$ de 27 de setembro de 2006. Dispõe sobre a distribuição gratuita de medicamentos e materiais necessários à sua aplicação e monitoramento da glicemia capilar aos portadores de diabetes inscritos em programas de educação para diabéticos Diário Oficial da União, Brasília. 2006.

Ministério da saúde. Portaria $\mathbf{n}^{\mathbf{0}}$ 2.583, de 10 de outubro de 2007. Define o elenco de medicamentos e insumos disponibilizados pelo SUS, nos termos da Lei $\mathrm{n}^{\circ} 11.347$, aos usuários portadores da Diabetes Mellitus. Diário Oficial da União, Brasília. 2007.

Conselho Nacional de Saúde. Resolução no 338, de 06 de maio de 2004. Política Nacional de Assistência Farmacêutica. Brasil.

COSEMS. Resolução $\mathbf{n}^{0}$ 182, de 11 de outubro de 2013. Pactua as normas de financiamento e de execução do Componente Básico da Assistência Farmacêutica no âmbito do Sistema Único de Saúde (SUS), no Estado do Pará. 2013.

DRESCH, Renato Luís. Federalismo solidário: a responsabilidade dos entes federativos na área da saúde. In: SANTOS, Lenir; TERRAZAS, Fernanda (Org.). Judicialização da saúde no Brasil. Campinas, Sp: Saberes Editora, 2014.

GEBRAN NETO, João Pedro; DRESCH, Renato Luís. A responsabilidade solidária e subsidiária dos entes políticos nas ações de saúde. Revista do Tribunal Regional Federal Quarta Região, Porto Alegre, v. 84, n. 25, p.1-680, 2014. Bimensal. Disponível em: <www2.trf4.jus.br>. Acesso em: 03 fev. 2015.

FREITAS, Cristina Leitão Teixeira de. Judicialização da saúde, solidariedade e ressarcimento: destaque da posição dos Estados frente à polarização de entendimentos. In: SANTOS, Lenir; TERRAZAS, Fernanda (Org.). Judicialização da saúde no Brasil. Campinas, Sp: Saberes Editora, 2014.

LIMA, Luciana Dias de. Federalismo, descentralização e regionalização na política de saúde do Brasil. In: ASENSI, Felipe Dutra; PINHEIRO, Roseni (Org). Direito Sanitário. Rio de Janeiro: Elsevier, 2012.

PALÁCIOS, Fernando Rocha. A cooperação federativa nas políticas públicas de educação básica: análise das políticas de financiamento, propostas do Governo Federal e dos educadores. 325 f. Dissertação (Mestrado) - Curso de Direito, Políticas Públicas e Desenvolvimento Regional., Programa de Pós-graduação Stricto Sensu em Direito, Centro Universitário do Estado do Pará - CESUPA, Belém, 2016. 
SANTOS, Lenir. Sistema Único de Saúde: os desafios da gestão interfederativa. Campinas, SP: Saberes Editora, 2013.

SARMENTO, Daniel; TELLES, Cristina. Judicialização da saúde e responsabilidade federativa: solidariedade ou subsidiariedade? In: ASENSI, Felipe Dutra; PINHEIRO, Roseni (Org.). Direito Sanitário. Rio de Janeiro: Elsevier, 2012.

WHITING, David R. et al. Atlas de Diabetes da IDF: Estimativas globais da prevalência de diabetes para 2011 e 2030. Diabetes Research and Clinical Practice, 2011, Volume 94, Edição $3,311-321$

\section{ANEXO I}

Em resposta ao SIC 1821623, formulada pela da cidadã Andreza Casanova Vongrapp Santos que solicita:

"Informações sobre ações judiciais para fornecimento de medicamentos

Prezados,

Solicito as seguintes informações sobre ações judiciais que demandaram medicamentos contra a União:

1) Quanto o Ministério da Saúde despendeu para dar cumprimento à ações de judiciais para fornecimento de medicamentos no período de 2011 à 2015?

2) Quais os medicamentos mais solicitados no ano de 2015 nas ações judiciais em saúde, demandas contra a União?"

O Departamento de Logística em Saúde - DLOG/SE/MS esclarece que:

1. Compete ao DLOG/SE/MS, segundo o Decreto Federal n. 8.065, de 7 de agosto de 2013, a atividade de planejar, coordenar, orientar e avaliar as atividades de compra de bens e de contratação de serviços relativos a insumos estratégicos para a saúde demandados por diversas áreas finalísticas desta Pasta Ministerial.

2. Este Departamento esclarece que de 2011 a 2015, a União dispendeu com demandas judiciais os valores discriminados na tabela abaixo:

\begin{tabular}{|l|c|}
\hline 2011 & $\mathrm{R} \$ 198.953 .470,14$ \\
\hline 2012 & $\mathrm{R} \$ 287.832 .182,50$ \\
\hline 2013 & $\mathrm{R} \$ 438.255 .243,83$ \\
\hline 2014 & $\mathrm{R} \$ 698.831 .712,49$ \\
\hline 2015 & $\mathrm{R} \$ 1.013 .331 .821,30$ \\
\hline Total & $\mathbf{R} \$ \mathbf{2 . 6 8 3 . 8 5 5 . 4 9 9 , 8 9}$ \\
\hline
\end{tabular}

* Compras realizadas pelo DLOG. Não se incluem neste número o atendimento por meio de depósito judicial. 
3. Quanto aos medicamentos mais demandados em 2015, foi realizado o levantamento com o 30 (trinta) mais pedidos, conforme planilha abaixo:

\begin{tabular}{|c|c|c|}
\hline MEDICAMENTO/ITEM & VALOR (R\$) & QTD (processos de compra) \\
\hline $\begin{array}{l}\text { INSULINA, GLARGINA, } \\
\text { 100UI/ML, INJETÁVEL }\end{array}$ & $338.233,46$ & 183 \\
\hline $\begin{array}{l}\text { REAGENTE PARA } \\
\text { DIAGNÓSTICO CLÍNICO, } \\
\text { QUANTITATIVO DE } \\
\text { GLICOSE, CAPILAR, TIRA }\end{array}$ & $110.434,40$ & 108 \\
\hline $\begin{array}{l}\text { INSULINA, ASPART, } \\
\text { 100U/ML, INJETÁVEL }\end{array}$ & $42.965,31$ & 86 \\
\hline $\begin{array}{l}\text { INSULINA, LISPRO, } \\
\text { 100U/ML, INJETÁVEL }\end{array}$ & $55.377,02$ & 85 \\
\hline $\begin{array}{l}\text { LANCETA, AÇO } \\
\text { INOXIDÁVEL,PONTA }\end{array}$ & $24.237,12$ & 64 \\
\hline $\begin{array}{l}\text { ECULIZUMABE, } 10 \text { MG/ML, } \\
\text { SOLUÇÃO INJETÁVEL }\end{array}$ & $369.963 .304,00$ & 50 \\
\hline $\begin{array}{l}\text { BEVACIZUMABE, } 25 \\
\text { MG/ML, SOLUÇÃO } \\
\text { INJETÁVEL }\end{array}$ & $3.196 .367,49$ & 42 \\
\hline $\begin{array}{l}\text { ICATIBANTO ACETATO, } 10 \\
\text { MG/ML, SOLUÇÃO } \\
\text { INJETÁVEL }\end{array}$ & $921.913,14$ & 40 \\
\hline $\begin{array}{l}\text { ABIRATERONA ACETATO, } \\
250 \mathrm{MG}\end{array}$ & $5.201 .781,60$ & 36 \\
\hline $\begin{array}{l}\text { TIOTRÓPIO BROMETO, } \\
\text { SAL BROMETO, } 2,5\end{array}$ & $116.771,62$ & 34 \\
\hline $\begin{array}{l}\text { CETUXIMABE, } 5 \text { MG/ML, } \\
\text { SOLUÇÃO INJETÁVEL }\end{array}$ & $2.653 .427,18$ & 32 \\
\hline OMEPRAZOL, $20 \mathrm{MG}$ & $11.528,98$ & 29 \\
\hline $\begin{array}{l}\text { INIBIDOR DE ESTERASE, } \\
\text { INIBIDOR DE ESTERASE } \\
\text { C1 HUMANA, } 500 \text { UI, PÓ } \\
\text { LIÓFILO PARA INJETÁVEL }\end{array}$ & $14.088 .143,71$ & 29 \\
\hline $\begin{array}{l}\text { INSULINA, GLULISINA, } 100 \\
\text { UI/ML, SOLUÇÃO } \\
\text { INJETÁVEL, REFIL }\end{array}$ & $8.871,66$ & 27 \\
\hline CINACALCETE, $30 \mathrm{MG}$ & $497.813,40$ & 27 \\
\hline CLOPIDOGREL, $75 \mathrm{MG}$ & $26.493,46$ & 27 \\
\hline
\end{tabular}




\begin{tabular}{|c|c|c|}
\hline $\begin{array}{l}\text { INSULINA, DETEMIR, } \\
\text { 100U/ML, SOLUÇÃO } \\
\text { INJETÁVEL }\end{array}$ & $35.252,35$ & 26 \\
\hline SINVASTATINA, $20 \mathrm{MG}$ & $8.303,40$ & 25 \\
\hline $\begin{array}{l}\text { ELOSULFASE ALFA, } 1 \\
\text { MG/ML, SOLUÇÃO } \\
\text { INJETÁVEL }\end{array}$ & $70.635 .232,53$ & 25 \\
\hline $\begin{array}{l}\text { ÁCIDO } \\
\text { URSODESOXICÓLICO, } 300 \\
\text { MG }\end{array}$ & $129.198,60$ & 25 \\
\hline $\begin{array}{l}\text { OMALIZUMABE, } 150 \text { MG, } \\
\text { PÓ LIÓFILO P/ INJETÁVEL }\end{array}$ & $1.016 .640,08$ & 24 \\
\hline $\begin{array}{l}\text { TERIPARATIDA, } 250 \\
\text { MCG/ML, SOLUÇÃO } \\
\text { INJETÁVEL, COM } \\
\text { SISTEMA DE APLICAÇÃO }\end{array}$ & $405.668,73$ & 23 \\
\hline $\begin{array}{l}\text { INSULINA, GLULISINA, } 100 \\
\text { UI/ML, SOLUÇÃO } \\
\text { INJETÁVEL }\end{array}$ & $8.491,67$ & 23 \\
\hline CLONAZEPAM, 2 MG & $3.960,00$ & 23 \\
\hline TEMOZOLOMIDA, $100 \mathrm{MG}$ & $889.309,40$ & 22 \\
\hline SOFOSBUVIR, $400 \mathrm{MG}$ & $2.642 .107,79$ & 22 \\
\hline $\begin{array}{l}\text { ALFA-1 ANTITRIPSINA } \\
\text { (AAT), } 1000 \text { MG, PÓ } \\
\text { LIÓFILO P/ INJETÁVEL }\end{array}$ & $2.080 .973,94$ & 21 \\
\hline $\begin{array}{l}\text { BORTEZOMIBE, 3,5 MG, } \\
\text { INJETÁVEL }\end{array}$ & $1.245 .287,99$ & 21 \\
\hline $\begin{array}{l}\text { SUNITINIBE, MALATO, } 50 \\
\text { MG }\end{array}$ & $2.159 .233,16$ & 20 \\
\hline $\begin{array}{l}\text { USTEQUINUMABE, } 90 \\
\text { MG/ML, SOLUÇÃO } \\
\text { INJETÁVEL }\end{array}$ & $550.379,69$ & 19 \\
\hline $\begin{array}{l}\text { RANIBIZUMABE, } 10 \\
\text { MG/ML, SOLUÇÃO } \\
\text { INJETÁVEL, C/SISTEMA } \\
\text { DE APLICAÇÃO }\end{array}$ & $485.989,96$ & 19 \\
\hline
\end{tabular}

4. Este Departamento coloca-se à disposição do interessado para eventuais esclarecimentos.

Breno Vilela Costa

Diretor

Departamento de Logística em Saúde - DLOG/SE/MS 